\begin{tabular}{|c|c|c|}
\hline PORT SAID ENGINEERING RESEARCH JOURNAL \\
Faculty of Engineering - Port Said University \\
Volume 17 No. 1 pp: 79:87
\end{tabular}

\title{
Application of Pile Fender system for Upgrading of Existing Quay
}

\author{
Sherif Abdellah \\ Associate Prof., Civil Eng. Dept., Faculty of Engineering, Port-Said University, Port-Said, EGYPT. \\ Email: sherifabdellah@yahoo.com
}

\begin{abstract}
A 120-m length, loading/unloading, pier at Kuwait Naval Base (KNB) is an open quay type. The pier face was protected by timber fender piling system. The system did not include any wale members. Both of the fender and pier elements undergo multiple deterioration. Urgently, the loading pier is expected to receive a bigger ship size than the designed one (6000 ton). The expected size of cargo ship is 10000-40000 ton. It was requested to install a fendering system in such a way to perform the next major concrete repair easily and limit the eccentric berthing reaction force to $450 \mathrm{KN}$. Therefore, the proposed fender system was completely detached from the quay. To meet the condition of allowed horizontal reaction force we employed the fender piles as part of berthing forces absorption system. This was effective approach where about $15 \%$ of the energy absorbed by the pile itself before the fender touch the copping beam, and then it absorbs about $10 \%$ after the fender had been deflected. The balance of the energy is absorbed by the fender units itself. Eventually, the performance of overall system resulted in reaction force less than the limit value and safe operation.
\end{abstract}

\section{Introduction}

The 120-m length, loading/unloading, pier at Kuwait Naval Base (KNB), shown in Figs. 1 and 2, consists of loading pier, north and south access bridges, piles, piles caps, stringers, and deck facilities. The pier face was protected by timber fender piling system. It contains a row of timber piles. Each pile faces a cylindrical rubber bumper. The system did not include any wale members rather than two rows of chock beams to transfer the lateral loads to the piles which, accordingly, transmit it directly to the bumpers (see fig.3). The bumper was fixed and connected to the quay head beam via anchors and chains.

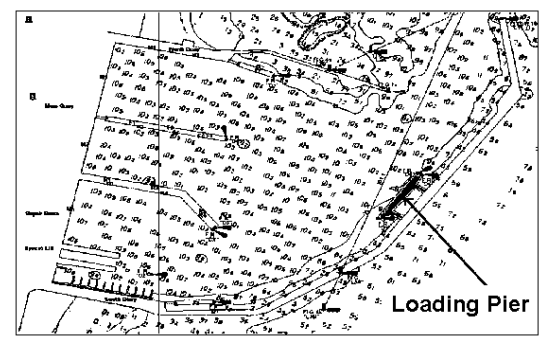

Fig. (1) Layout of Kuwait Naval Base; KNB

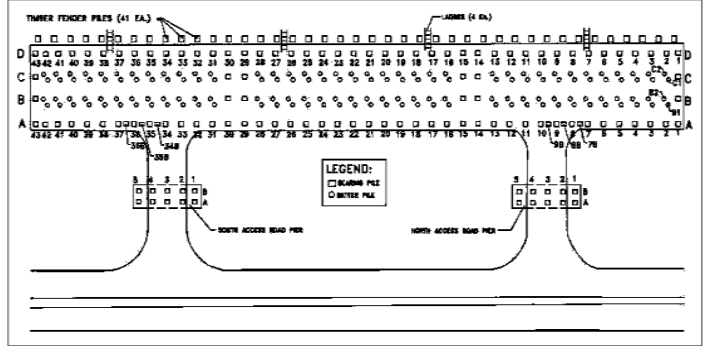

Fig. (2) General Arrangement of Loading Pier

Recently, the loading pier is expected to receive a bigger ship size than the designed one (6000 ton). The expected size of cargo ship is 10000-40000 ton. Unlikely, most of the pier units undergo multiple deterioration in most concrete elements and pile fender elements.

In fact, the existing 30-year old timber fender piling system was determined to be at the end of its useful service life. So, both of the quay concrete elements and fender piling system are in need to an immediate repair action to save and maintain its vital service. This repair is expected to last some time. Therefore, due to the vitality of the loading pier function, it was decided to execute innovation works for the fender system ahead of the pier repair works. 


\subsection{Wind and waves}
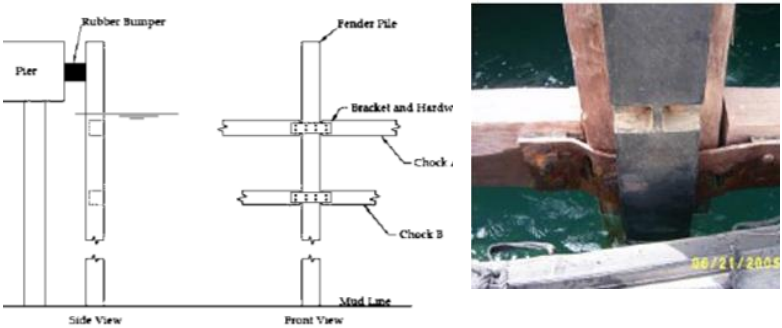

Fig. (3) Old Fender Piling System (No wale members)

Some conditions were recommended in the desired innovative fender system as; the bumper should not fasten on the quay copping beam because of its deteriorate condition and to not impede the concrete repair works. The fender system can deal with a wide range of vessel sizes (10 ton- 31500 ton). The fender reaction force should be transmitted to a wide length of the quay face to relieve the impacted horizontal forces on the structural system. Maximum eccentric lateral reaction force should not exceed $450 \mathrm{KN}$.

\section{Site and operation conditions}

The Pier length is $120 \mathrm{~m}$ and width is $15 \mathrm{~m}$. The quay concrete elements undergo a multiple cracking and deterioration as shown in fig. (4). Also, the chock beams positions and its connections were in poor conditions as shown in fig. (3). Therefore, the concrete elements are in need to an immediate repair works. The repair required intensive field tests as loading tests, analysis of results, and proper procedure to repair all cracks in pier deck, pile caps, and stringers using pressure grouting, epoxy injection or other acceptable crack sealing method. The fender system is replaced with a new one, with 20 years design life time, to deal with the target bigger ship size.
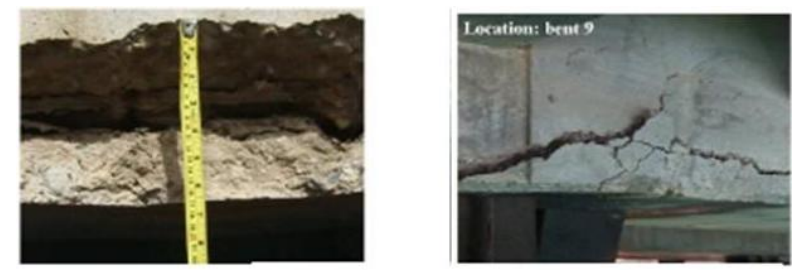

Fig. (4) Record of Concrete Elements Deterioration

\subsection{Water depth and tide}

The existing water depth is $10.25 \mathrm{~m}$ (ACD). The Arabian Gulf is known with its high tidal range. The tidal levels could be briefed as;

Highest Astronomical Tide $($ HAT $)=+3.18$

Mean High water spring $($ MHWS $)=+2.84$

MSL $=+1.80$

MLWS $=+0.48$
The Prevailing wind direction is North-West and its extreme speed is $120 \mathrm{~km} / \mathrm{hr}$ (3-sec. gust). The waves within the water basin do not exceed $50 \mathrm{~cm}$ for the 1 in 1 year return period. It is extrapolated to 1 in 100 year as $100 \mathrm{~cm}$.

\subsection{Criteria of the new target ships}

There are two target ships as shown in table (1);

Table 1: Ship Parameters

\begin{tabular}{|l|l|l|}
\hline Parameter & Ship-1 & ship-2 \\
\hline DWT [Ton] & 10000 & 40000 \\
\hline $\mathrm{L}_{\mathrm{OA}}[\mathrm{m}]$ & 100 & 200 \\
\hline $\mathrm{L}_{\mathrm{BP}}[\mathrm{m}]$ & 90 & 175 \\
\hline B $[\mathrm{m}]$ & 16.9 & 29 \\
\hline $\mathrm{D}[\mathrm{m}]$ & 6.6 & 10 \\
\hline
\end{tabular}

Where; DWT: Dead Weight Tonnage

$\mathrm{L}_{\mathrm{OA}}$ : Overall Length

$\mathrm{L}_{\mathrm{BP}}$ : Length between perpendiculars

B: Beam width

D: Ship draft

\subsection{Soil properties}

The seabed soil is granular in general. It ranges from medium dense silty sand at the first 3 meter to dense silty sand at the next layers.

\section{The Principle of new fender system}

The use of efficient fenders decreases the cost of waterfront structure and increases its life time. The cost of vessels is on increase; however strength of the outer hull is being reduced further and further. This trend demand good fendering system.

A fender is, in principle, the intermediate layer between vessel and waterfront structure. This intermediate layer absorbs part of the kinetic energy of a berthing ship; indeed, an energy-absorbing fender will absorb most of this energy. But of course, the waterfront structure itself and the ship's hull also absorb some of the energy through their elasticity/ plasticity, refer to fig. (5).

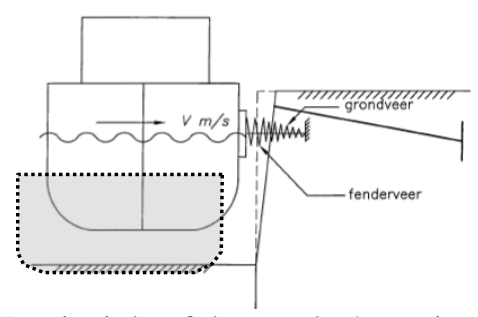

Fig. (5) Principle of the Fender/quay interaction 
The energy absorption of a fender is the area beneath the curve of deformation against reaction force. Once the absorption capacity of the fender reached, the reaction force transfer to the structure. Therefore, an adequate factor of safety against the fender reaction force should be considered.

The properties (e.g. load-deflection curve) of various fenders can be found in the publications of the fender manufacturers. However, it should be mentioned that these curves apply only when the fender cannot buckle sideways and when the creep under permanent load is not excessive.

When study the fender support structures, it is not only the berthing loads that must be taken into account. The horizontal and vertical movements of the ship during berthing and departure, the loading and unloading procedures, swell or fluctuations in the water level, etc. can lead to friction forces in the horizontal and/or vertical direction (provided these movements are not accommodated by the rotation of suitable fenders).

The new fender system consists of a rubber fender behind a standard steel piles fender. The rubber is attached only to the piles and completely detached from the loading and unloading pier, refer to fig. (6). The advantages of this system is that it allows the repair of the pier while the fender system is in service, it eliminates the friction forces effect as it will be absorbed by the pile system itself and thus the fender almost will be subject to horizontal forces only, and the wale beam and cross chock beams make the fender system perform as a group which enhance berthing absorption as explained later. Thick Marine timber is used to cover all steel parts in touch with the ship.

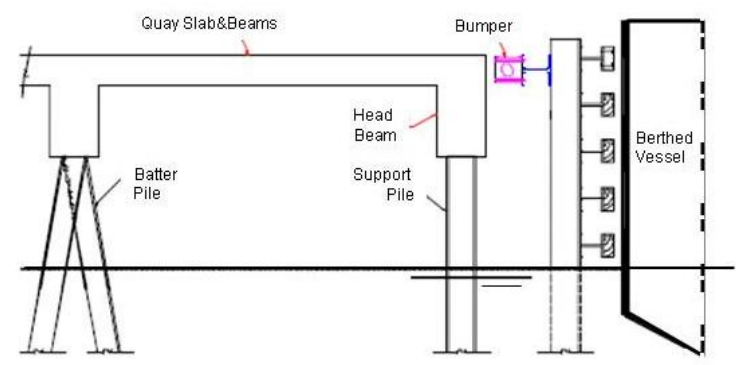

Fig. (6) Principle of the Fender/quay interaction

\section{Berthing operation and energy}

\subsection{Berthing velocity}

Berthing velocity is an important parameter in fender system design. It depends on the size of the vessel, loading condition, port structure, and the ease of difficulty of the approach. When the actual measured velocity is not available, the most widely used guide to estimate the berthing velovity is the Brolsma chart [2].
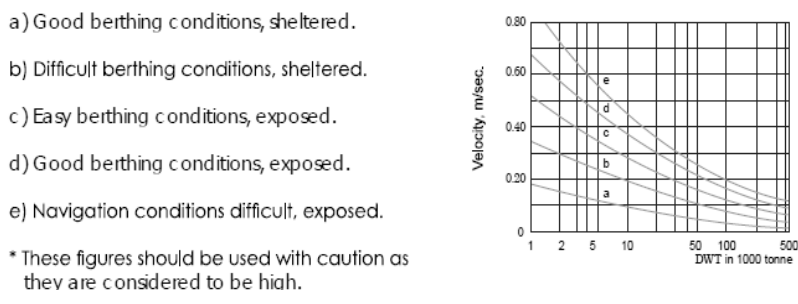

Fig. (7) Berthing Velocities Chart, [2]

Under this port conditions, the recommendation is to assume the berthing velocity as $0.20 \mathrm{~m} / \mathrm{s}$.

\subsection{Berthing direction}

The ship usually approaches with some angle, like 10 or 15 degree, to the quay where it contacts to one fender or two fenders. The ship may also have parallel berthing where ship contacts the plural fenders. In the first case, the fender should have enough capacity to absorb berthing energy. Usually, it is subjected to angular compression due to friction between the hull and the fender. As discussed earlier in section 3.0, the proposed fender system will minimize the fender angular compression as shown in fig. (8). Under this port operation condition, the ship- 1 , which is the frequent size, will self-berth while ship-2 will berth parallel to the quay with tug assistance.

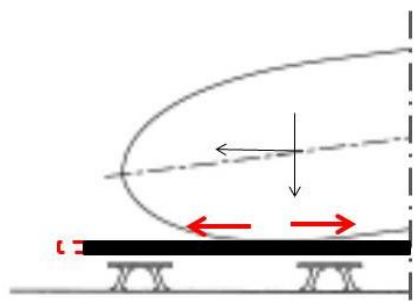

Fig. (8) Berthing with angle to pile fender system

\subsection{Hull contact pressure}

When we design the berthing facility for a ship, we should consider the impact force on the ship's hull; (the maximum reaction force divided by the area of contact between fender front and ship). Permissible hull pressures vary greatly with the class and size ship. The best guide to hull pressure is the designer's experience in similar cases. In our case study the limit hull contact pressure is $14.6 \mathrm{psi}$.

\subsection{Contact surface between a vessel and fender System}

Usually, the ship bow radius, fender, and fender deflection are used to determine the spacing between fender units. In this case study, there is no chance to have a direct contact between the fender units and the 
ship hull. In every approach angle the ship will contact the pile-chock beams at first. Then, the system displaces to transfer the energy to rubber fender and back structure.

To estimate the size of contact surface, accurate drawing for ship-1 hull outline has been done for two different berthing angles; $6^{\circ}$ and $10^{\circ}$. The minimum width is found as $12.0 \mathrm{~m}$. Refer to fig. (8).

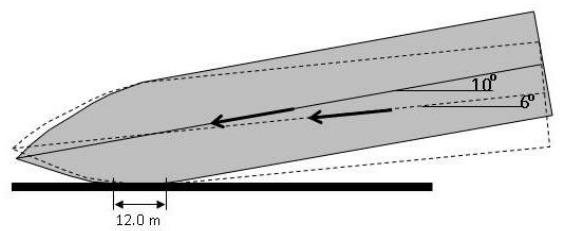

Fig. (8) Estimation of vessel-fender contact length For ship-1

\subsection{Berthing energy}

According to BS 6349-4, the berthing energy could be expressed as:

$$
E=0.50 C_{M} M_{D}\left(V_{B}\right)^{2} C_{E} C_{S} C_{C}
$$

Where:

E: Berthing Energy (KN.m)

$\mathrm{C}_{\mathrm{M}}$ : Hydrodynamic mass coefficient.

$\mathrm{M}_{\mathrm{D}}$ : Ship displacement (ton)

$\mathrm{V}_{\mathrm{B}}$ : Approach velocity $(\mathrm{m} / \mathrm{s})$

$\mathrm{C}_{\mathrm{E}}$ : Eccentricity Coefficient

$\mathrm{C}_{\mathrm{S}}$ : Softness Coefficient

$\mathrm{C}_{\mathrm{C}}$ : Berthing configuration coefficient. For open structure (platform on piles), $\mathrm{C}_{\mathrm{C}}=1.0$

According to Vasco Costa method; [2], the $\mathrm{C}_{\mathrm{M}}$ estimated as;

$\mathrm{C}_{\mathrm{M}}=1+2 \mathrm{D} / \mathrm{B}$

From BS 6349-4, the $C_{\mathrm{E}}$ could be estimated as follows:

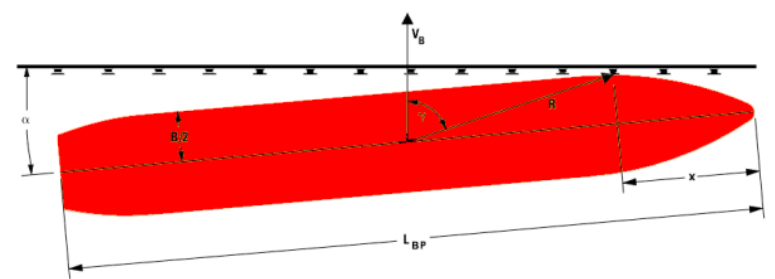

Fig. (9) Ship parameters to estimate $C_{E}$

$C_{E}=\frac{K^{2}+R^{2} \cos ^{2} \gamma}{K^{2}+R^{2}}$

Where $\mathrm{K}$ is radius of gyration

$$
=\left[0.19 \mathrm{C}_{\mathrm{B}}+0.11\right] \mathrm{L}_{\mathrm{BP}}
$$

The block coefficient $\left(\mathrm{C}_{\mathrm{B}}\right)=\frac{M_{D}}{L_{B P} B D \rho_{W}}$

Then, $\mathrm{C}_{\mathrm{B}}=0.67$, and $\mathrm{K}=24.68 \mathrm{~m}$

The distance between the contact surface center and the center of mass, R:

$R=\sqrt{\left(\frac{L_{B P}}{2}-X\right)^{2}+(B / 2)^{2}}$

Assume Quarter - point

$X=L_{B P} / 4$

$\gamma=90^{\circ}-\alpha-\sin ^{-1}(B / 2 R)$

Where approach angle $(\alpha)=10^{\circ} \quad$ for ship-1

But ship-2 approaches parallel to the quay.

According to ship parameters in item 2.3, the energy parameters and value are concluded in table- 2 .

Table 2: Berthing Energy

\begin{tabular}{|l|c|c|c|c|c|c|}
\hline Case & $\mathrm{C}_{\mathrm{M}}$ & $\mathrm{C}_{\mathrm{E}}$ & $\mathrm{Cs}$ & $\mathrm{Cc}$ & $\begin{array}{c}\mathrm{V}_{\mathrm{b}} \\
(\mathrm{m} / \mathrm{s})\end{array}$ & $\begin{array}{c}\mathrm{E} \\
(\mathrm{kN} . \mathrm{m})\end{array}$ \\
\hline Ship-1 & 1.78 & 0.57 & 0.90 & 1 & 0.25 & 285 \\
\hline Ship-2 & 1.67 & 1 & 0.90 & 1 & 0.20 & 1200 \\
\hline
\end{tabular}

\section{Model parameters and setup}

\subsection{Pile- Soil Interaction Modelling Procedure}

The ultimate resistance of a vertical pile to a lateral load and the deflection of the pile as load builds up to ultimate value are complex matters involving the interaction between a semi-rigid structural element and the soil, which deforms partly elastically and partly plastically. But a simple method to calculate the ultimate load is to assume an arbitrary Depth; $\mathrm{Z}_{\mathrm{f}}$ to the point of virtual fixity:

A partly-embedded pile carrying a vertical load $\mathrm{P}$, a horizontal load $\mathrm{H}$, and a moment $\mathrm{M}$ at a height; e above the ground surface and the equivalent height; Le, of the fixed-base pile is shown in fig. (10):

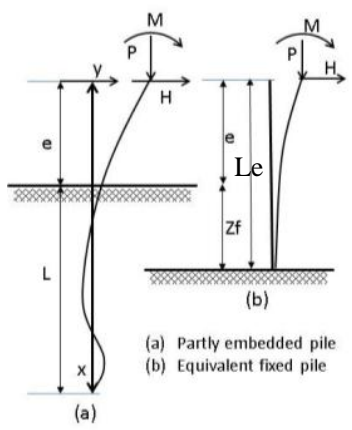

Fig. (10) Bending of pile carrying vertical and horizontal loads at head; [9] 
This depth can be calculated on assumption that pile behaves as an elastic beam on the soil which also behaves elastically. For soils having a linearly-increasing modulus:

$\mathrm{Z}_{\mathrm{f}}=1.8 \mathrm{~T}$

Stiffness Factor $T=\sqrt[5]{\frac{E I}{n_{h}}}$ (in units of length)

$\mathrm{E}=2.0 \times 10^{8}$ ton $/ \mathrm{m}^{2}$, steel elasticity modulus

$\mathrm{I}=0.00037 \mathrm{~m}^{4}, \mathrm{HP} 35$ initial fender steel pile

$\mathrm{n}_{\mathrm{h}}=3000$ ton $/ \mathrm{m} 3$, coefficient of subgrade modulus for

Then, $\mathrm{T}=1.90 \mathrm{~m}$ medium to dense sand, [10]

$\mathrm{Z}_{\mathrm{f}}=3.40 \mathrm{~m}$
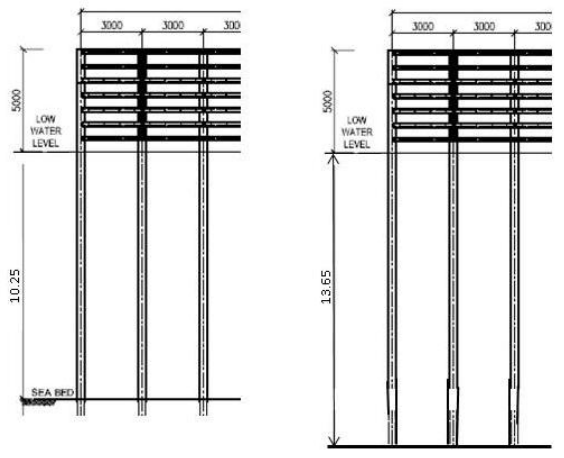

Fig. (11) Actual and virtual pile free length

\subsubsection{Modelling of pile fender system}

The case modelling philosophy is based on subdividing the berthing energy absorption process into two successive phases as shown in fig. (12). The first phase represents the fender pile just before be touched by the approached ship. Clearance between the system and the quay copping beam is set at initial distance; $\mathrm{S}_{\mathrm{o}}$.

The second phase is the fender when be shocked by the approached ship. The pile moved freely till it touches the copping beam. The clearance distance is $S_{1}$. At the third phase the system force the fender unit, it starts absorbing the energy according to its designed capacity. At this phase, the clearance distance becomes more small; $S_{2}$.

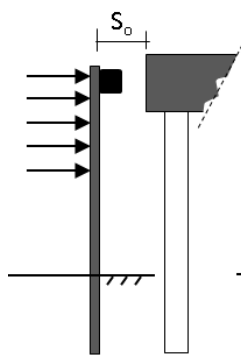

(1)

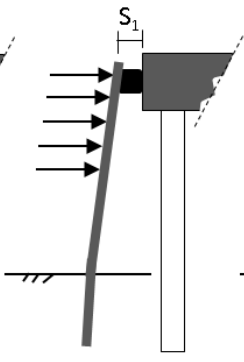

(2)

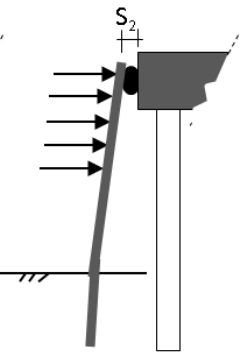

(3)
Fig. (12) Phases of Berthing energy Absorption
Therefore, the total berthing energy; $\mathrm{E}$ could be expressed as follows;

$$
\mathrm{E}=\mathrm{E}_{1}+\mathrm{E}_{2}+\mathrm{E}_{3}
$$

Where:

$\mathrm{E}_{1}$ : Energy absorbed by free pile system

$\mathrm{E}_{2}$ : Energy absorbed by pile system when got additional excursion (due to fender squeezing).

$\mathrm{E}_{3}$ : Energy absorbed by the fender unit itself

\subsubsection{Free cantilever Piles system}

The pile fender system shown in figs. (6 and 11) is modelled using a 3D finite element method (SAP 2000, Ver. 14). The model elements are shown in fig. (13) along with the applied loads location according to figs.(8 and 9). A proper estimation has been done for all the elements and the way of its fixation.

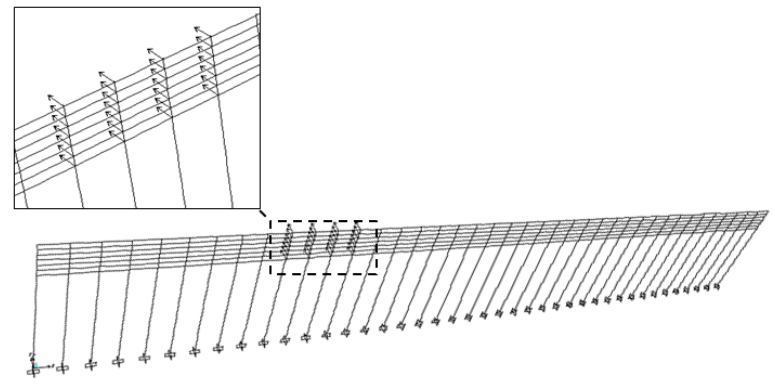

Fig. (13) Free fender pile system (cantilever type)

\subsubsection{Piles with equivalent spring at top end}

The same model discussed in 5.2.1 is modified as a second model. Each top pile end is supported by a spring as shown in fig. (14). The spring represents the rubber fender units. According to the quay beam geometry and the limit condition of lateral reaction force, hollow rectangular rubber fender of 12-inch size is estimated.

According to the performance curve (15), the spring coefficient; $\mathrm{K}=4000 \mathrm{KN} / \mathrm{m}$ which estimated as;

Where:

$$
\mathrm{K}=2 \mathrm{E}_{\mathrm{f}} / \mathrm{x}^{2}
$$

$\mathrm{x}$ : Deflection of fender (for linear load curve part) $\mathrm{E}_{\mathrm{f}}$ : Corresponding absorbed Energy/m 


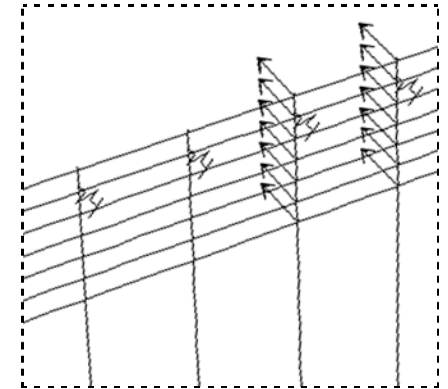

Fig. (14) Fender pile system supported by springs

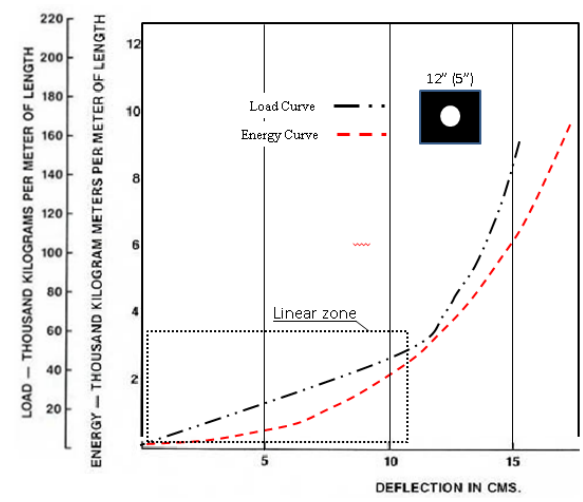

Fig. (15) Rectangular Fender performance curves

\section{The system performance under different operation conditions}

There are two main berthing operation cases as concluded in table (2); the first is the small ship approach freely at angular and touch the fender system at about quarter of its overall length; fig. (9). The second is the big ship approach, via tug assistance, and berth parallel to the fender system. The model study divided accordingly to four sections as follows;

1- The pile fender system acts freely under acting point load at each node for 12-m length around the quarter the overall quay length.

2- The same model as in 1, but with springs at each top end pile.

3- The pile fender system acts freely under acting load at each node overall the quay length.

4- The same model as in 1, but with springs at each top end pile.

We run these models for a set of applied loads values as; $2.5,5.0,10.0,15.0,20.0,25.0 \mathrm{KN}$. The horizontal components of displacement and force at each node are extracted for further analysis.
To estimate the energy absorbed by the pile system, we follow the following simple principle which satisfactory meets the target and accuracy required;

Energy is the ability a physical system to do work. When a force; F (constant with respect to time) acts on an object while the object is transnationally displaced for a displacement vector $\mathrm{d}$, the work done by the force on the object is the dot product of the vectors F and d; [3]

$$
\mathrm{W}=\mathrm{F} \cdot \mathrm{d}=\mathrm{Fd} \cos \Theta
$$

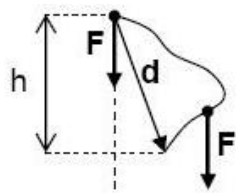

Fig. (16) Work main parameters

Thus the total work (W) of the pile fender system equal to the line integral of the force $\mathrm{F}$ along the displaced path. It could be expressed as follows;

$$
E=W=\sum_{1}^{n h} \sum_{1}^{n v} F_{x} . d_{x}
$$

Where:

nh: number of pile elements

nv: number of nodes of cross beams at each pile

$\mathrm{F}_{\mathrm{X}}, \mathrm{d}_{\mathrm{x}}$ : Force and displacement horizontal

Components

\subsection{Ship berthing with angular approach}

Under each applied loads, $2.5-25 \mathrm{KN}$, the displacement of each joint/node along the whole system is extracted from the model. Fig. (17-a) represents the system performance when it move freely as simple cantilever. It shows maximum displacement, at top pile level, against the system length under different applied loads. Fig. (17b) shows the same performance but under supporting the top end by springs (fender units).

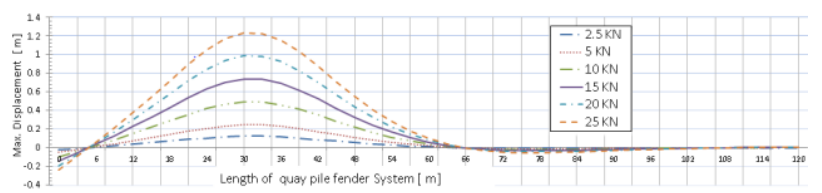

[a]

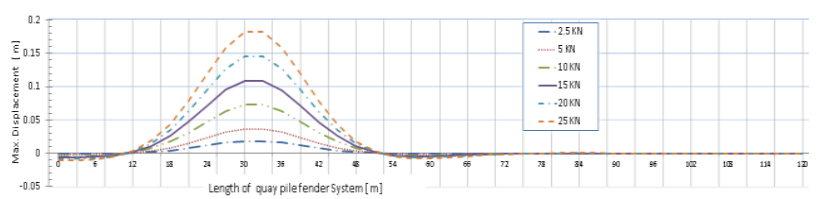

[b] 
Fig. (17) Distribution of pile-fender system displacement under different virtual acting forces

The loads were applied on $12.0 \mathrm{~m}$ of the system length, refer to fig. -8 , however due to the proposed structural system the displaced length is about 4-5 times the impacted length. This means that more elements shares in absorbing shake energy.

Fig. (18) represents the total absorbed energy, due to free cantilever piles according to eq. [11], against maximum displacement at top pile end. At $0.30 \mathrm{~m}$ displacement value, the absorbed energy is 45 KN.m.

Fig. (19) represents the total absorbed energy, due to spring-supported piles, against maximum displacement at top pile end. At $0.10 \mathrm{~m}$ displacement value, the absorbed energy is $30 \mathrm{KN} . \mathrm{m}$ and maximum reaction force is $450 \mathrm{KN}$. Reviewing fig. (17-b), the displacement curve with maximum displacement value $0.10 \mathrm{~m}$ is appropriate to this case study. For each displacement value of that curve, fig. (15), the energy to be absorbed by the rubber fender units is estimated as $220 \mathrm{KN} . \mathrm{m}$. Therefore, the total absorbed energy by the proposed pile fender system is the summation of the previous values; 45, 30, and $220 \mathrm{KN}$. This gives $295 \mathrm{KN}$.m which meets the estimated berthing energy sufficiently. At the same time, the maximum reaction force is $450 \mathrm{KN}$ which is less than the allowed eccentric maximum lateral force $(500 \mathrm{KN})$.

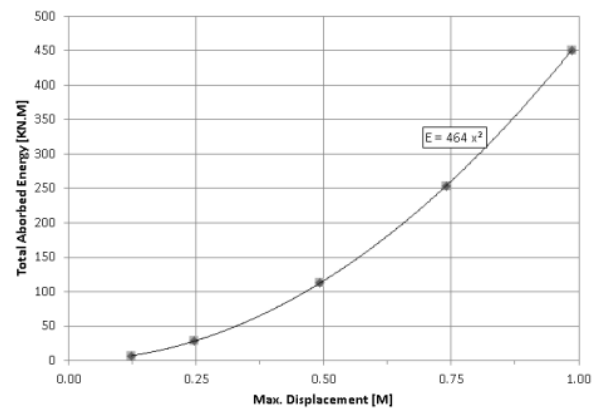

Fig. (18) Performance of pile-fender system under free cantilever conditions [angular approach].

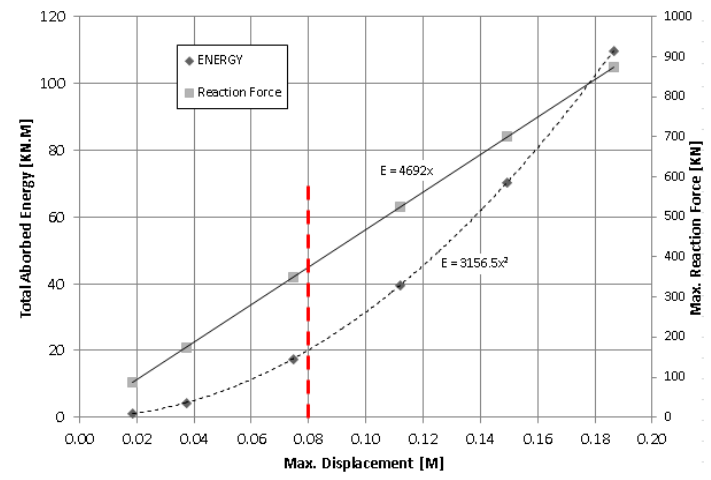

Fig. (19) Performance of pile-fender system under spring constraint conditions [angular approach].

\subsection{Ship berthing in parallel}

As discussed earlier, the loads were applied on all nodes along the overall quay length. Due to the proposed structural system and the approaching scenario, the nodes almost displaced equally.

Fig. (20) Represents the total absorbed energy, due to free cantilever piles according to eq. [11], against maximum displacement at top pile end. At $0.30 \mathrm{~m}$ displacement value, the absorbed energy is about 175 KN.m.

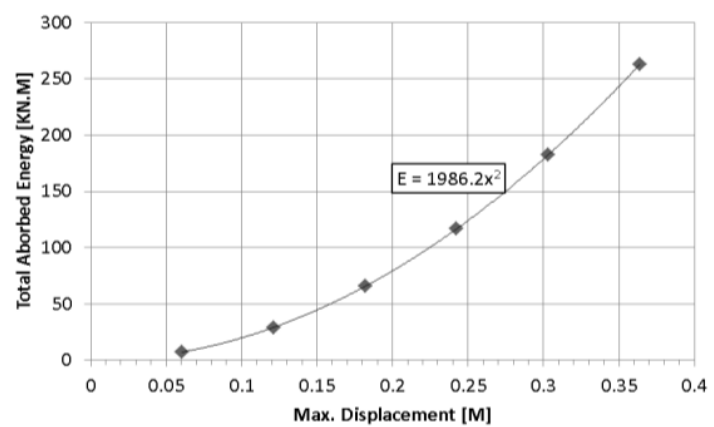

Fig. (20) Performance of pile-fender system under free cantilever conditions [Parallel approach].

Fig. (21) Represents the total absorbed energy, under spring constraint conditions, against maximum displacement. Under only $7.5 \mathrm{~cm}$ displacement, the absorbed energy is 100 KN.m and maximum reaction force is $10 \mathrm{KN}$. Referring to fig. (15), the fender can absorb about $10 \mathrm{KN} . \mathrm{m} / \mathrm{m}$. Along the quay length, there is about 40 fender units, each of $2.50 \mathrm{~m}$ length with $0.50 \mathrm{~m}$ gap. Thus, these units could absorb 1000 KN.m.

Therefore, the total absorbed energy under this approach conditions is the sum of $175,100,1000 \mathrm{KN} . \mathrm{m}$ as 1275 KN.m. This absorbing capacity meets the berthing energy of ship-2 (table-2).

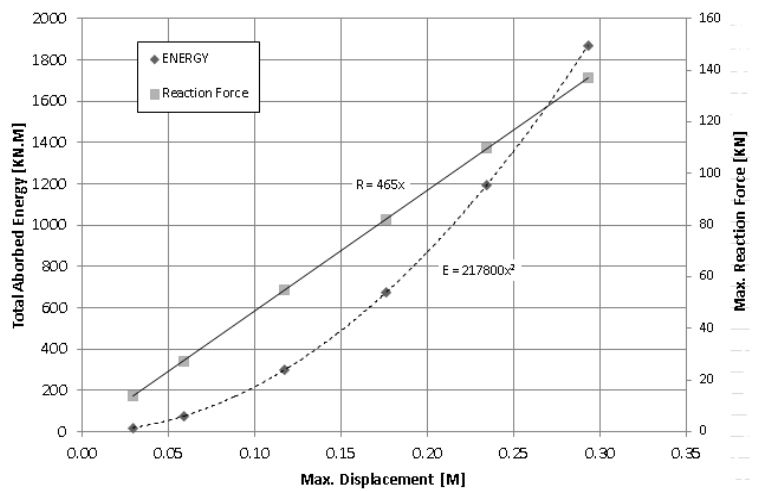


Fig. (21) Performance of pile-fender system under spring constraint conditions [Parallel approach].

\section{Analysis and Elements Selection}

The concept of the analysis approach for this case study depends mainly of sharing the pile elements in berthing energy absorption. To meet this concept, the pile steel section should be work within the elastic zone only. Therefore, the piles of I-35 is checked against the maximum acting straining forces; moment, shear, and normal for both case-1 and case- 2 of ship berthing modes. Table (2) and fig. (22) conclude the output of structural analysis which confirm that the piles can absorb the assumed energy portion within its elastic performance zone.

Table-2: Structural analysis output of Pile section

\begin{tabular}{|c|c|c|}
\hline \multirow{2}{*}{ Case } & Stress & Strain \\
\cline { 2 - 3 } & $\mathrm{N} / \mathrm{mm} 2$ & \\
\hline max stresses for section & 270 & 0.0014 \\
\hline allowable stresses for section & 140 & 0.0007 \\
\hline loads at specific joints; case-1 & 120 & 0.0006 \\
\hline loads at all joints; case-2 & 100 & 0.0005 \\
\hline
\end{tabular}

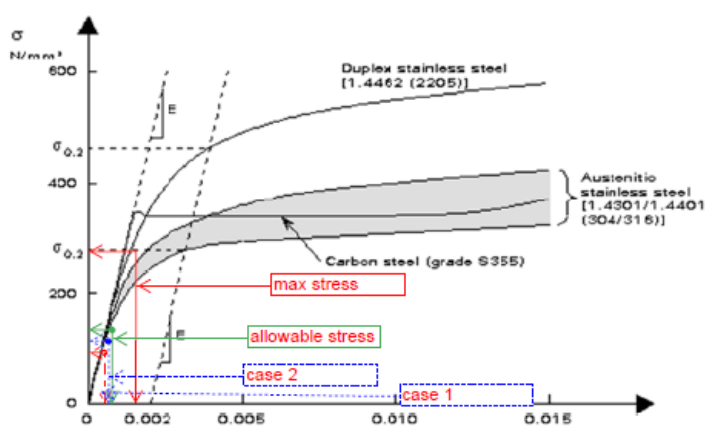

Fig. (19) Typical stress-strain curves for stainless and carbon steel $\left(\sigma_{02}\right.$ is $0.2 \%$ proof strength, E is Young's modulus), [9].

\section{Conclusion and Recommendation}

Port quays are usually designed to serve a certain ship size. At the end of the quay service life, we may apply some renovation methods to extend its service life. These methods deal with the quay safety against the applied vertical loads and horizontal loads (berthing/anchorage loads). In this paper we discussed a special case where not only we need to secure the old quay safety against the berthing forces but also arrange the fendering system in such a way to perform the next major concrete repair easily. The proposed fender system was completely detached from the quay. To meet the condition of allowed horizontal reaction force we employed the fender piles as part of berthing forces absorption system. This was effective approach where;

- About $15 \%$ of the energy absorbed by the pile itself before the fender touch the copping beam.

- Then it absorbs about $10 \%$ after the fender had been deflected.

- The balance of the energy is absorbed by the fender units itself.

- Eventually, the performance of overall system resulted in reaction force less than the limit safe one. Thus, the quay could serve a bigger ship size and its service life could be considerably extended.

Photos (1-4) record the discussed system after full installation and under operation. The quay and fender elements showed acceptable performance under both the angular and parallel berthing operations.

We recommend to extend this study in the field through force and displacement cells to monitor the performance under different berthing loads conditions.
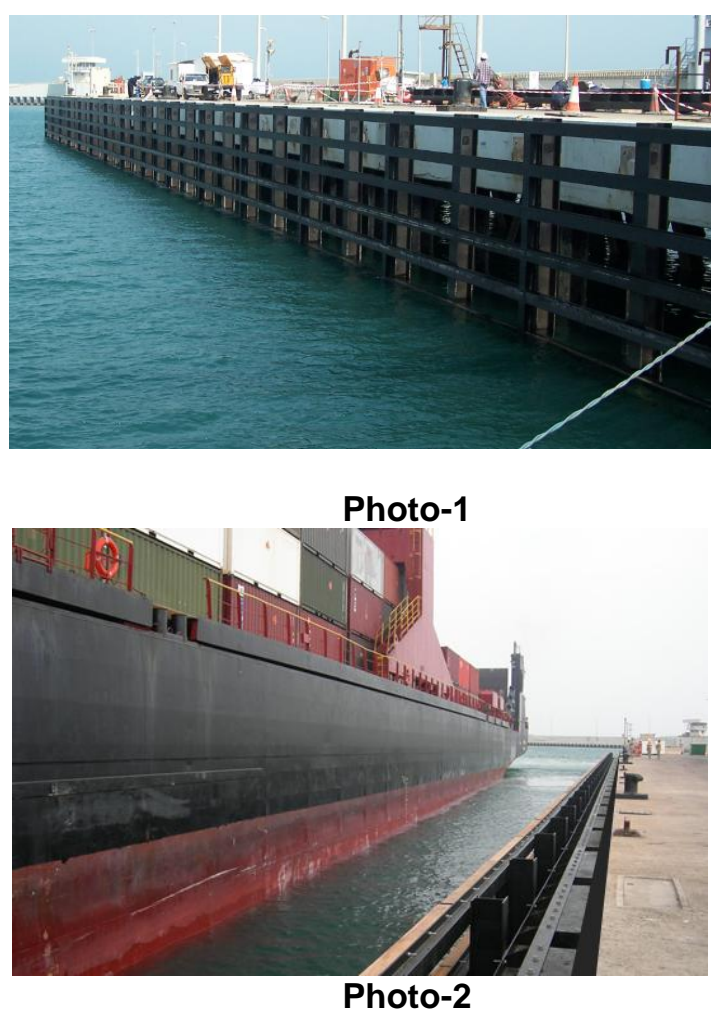


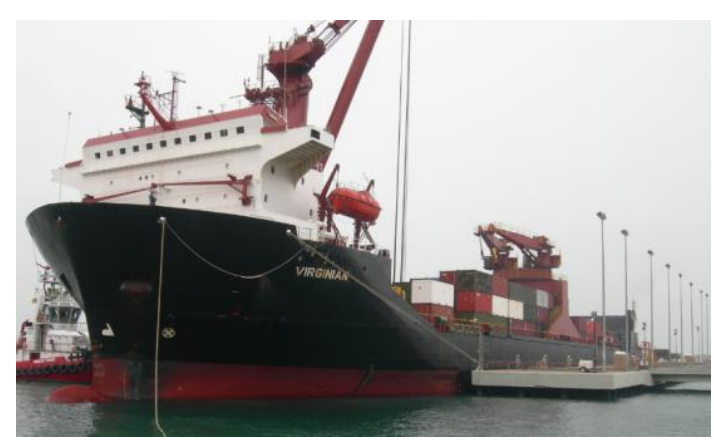

Photo-3

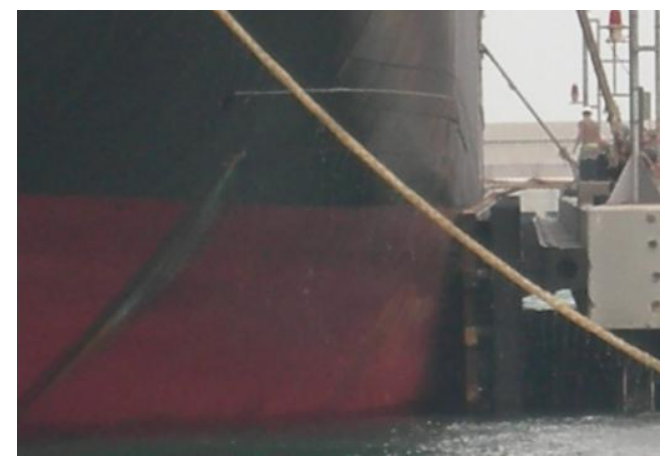

Photo-4
[6] Braja M. Das (2004) "Foundation Engineering", $5^{\text {th }}$ edition, THOMSON Brooks/Cole

[7] velocity Brolsma et al. 1997

[8] AISC, AMERICAN INSTITUTE OF STEEL CONST., INC., One East Wacker Drive, Suite 3100, Chicago, Illinois 60601-2000

[9] American Society for Testing and Materials (ASTM), 2004, West Conshohocken, PA, 19428-2959 USA

[10] 1985-2006, Quality Pacific Manufacturing, Inc.and Pacific Marine and Industrial_PM\&I

\section{References}

[1] CUR-166 Deel 2 (2005), "Civieltechnisch Centrum Uitvoering Research en Regelgeving; Damwandconstructies".

[2] Carl Thoresen (2003), "Port designer's Handbook", published by Thomas Telford Books.

[3] John Gaythwaite (2004), "Design of marine facilities for the berthing, mooring, and repair of vessels", 2nd edition, ASCE Press.

[4] SAP 2000; Static and dynamic Finite element Analysis of structures advanced 14.1.0, University of California, Berkely.

[5] M.J. Tomlinson (1997), "Pile Design and Construction Practice", $4^{\text {th }}$ edition, Taylor\&Francis publisher 